\title{
ANTIBACTERIAL ACTIVITY OF SILVER NANOPARTICLES COATED INTRAVASCULAR CATHETERS (AgNPs-IVC) AGAINST BIOFILM PRODUCING PATHOGENS
}

\author{
R. Sengodan ${ }^{1}$, R. Ranjithkumar ${ }^{2}$, K. Selvam ${ }^{3}$ and B. Chandarshekar ${ }^{4}$ \\ ${ }^{1}$ Department of Physics, Kumaraguru College of Technology, Coimbatore, Tamilnadu, India. \\ ${ }^{2}$ Department of Biotechnology, Nehru Arts and Science College, Coimbatore, Tamilnadu, India. \\ ${ }^{3}$ Department of Botany, Periyar University, Salem, Tamilnadu, India. \\ ${ }^{4}$ Nanotechnology Research Lab, Department of Physics, Kongunadu Arts and Science College, \\ Coimbatore, Tamilnadu, India \\ *E-mail: biotechranjith@gmail.com
}

\begin{abstract}
Nanotechnology encompasses the understanding of the fundamental physics, chemistry, biology and technology of nanometre-scale objects. The study of bactericidal nanomaterials is particularly timely considering the recent increase of new resistant strains of bacteria to the most potent antibiotics. In this present study, deals with antibacterial activity of green synthesized silver nanoparticles coated intravascular catheter (AgNPs-IVC) against biofilm producing human pathogens by Zone of inhibition (ZOI) standard microbiology assay. AgNPs-IVC shows excellent antibacterial activity against $S$. epidermidis and $K$. pneumoniae, ZOI around $42 \mathrm{~mm}$ and $36 \mathrm{~mm}$. The prepared AgNPs-IVC confirms moderate antibacterial activity against $S$. aureus, E. coli and $P$. aeruginosa, ZOI around 31, 28 and $27 \mathrm{~mm}$ respectively. In addition, SPTT study reveals that the AgNPs-IVC showed a long duration of activities up to Day $8^{\text {th }}$ against $K$. pneumoniae and $S$. epidermidis. Hence, to the utilization of green synthesized silver nanoparticles coated biomedical products to prevent biofilm formation and act as widespread antibacterial materials.
\end{abstract}

Keywords: Silver nanoparticles, AgNPs-ICV, Biofilm, ZOI, SPTT

(C) RASĀYAN. All rights reserved

\section{INTRODUCTION}

Nanotechnology is novel approaches to research phenomena at atomic, molecular and macromolecular scales, where properties differ significantly from those at a larger scale. This novel approach can be useful to microbial biofilms control, which is formed when bacterial and/or yeast cells adhere to abiotic and biotic surfaces. ${ }^{1}$ Nanomaterials have nanoscale dimensions about between 1-100 $\mathrm{nm}$ and frequently exhibit new and significantly chemical, physical and biological changed proprieties ${ }^{2}$ and nanoparticles have excellent catalysts, sensor and adsorbents due to their large specific surface area and high reactivity. ${ }^{3}$ The field that applied this technology to understand and transform biosystems can be defined as nanobiotechnology. ${ }^{4}$ Nanoparticles can present a unique alternative as detection methods of bacterial targets, in main nanosensors that could directly detect the presence of a particular pathogen agent or indirectly detect them through the assessment of the pathogens metabolic activity. ${ }^{5}$

Several engineered and natural nanoparticles including titanium dioxide ${ }^{6}$, zinc $^{7}$, silver $^{8}$ and gold ${ }^{9}$ have shown strong antimicrobial properties against human pathogens. Antimicrobial activity of nanoparticles are well known, of all the nanoparticles, silver nanoparticles have been described as the one with the highest level of toxicity for microorganisms and lowest toxicity for animal cells. ${ }^{10}$ The researcher reported that the plant extract assists synthesized AgNPs have recently appeared as new antimicrobial agents due to their high surface area to volume ration and unique chemical and physical properties. ${ }^{11,12}$ The antibacterial activity AgNPs The improvement of impregnation of medical devices with silver nanoparticles is that it protects both outer and inner surfaces of medical devices and there is the continuous release of silver ions providing good antimicrobial activity. ${ }^{13,14}$ In general, silver nanoparticles 
exploited towards the development of potential antibacterial material. In this study we demonstrate antibacterial activity of plant extract assisted silver nanoparticles coated Intravascular Catheters (AgNPsIVC) against Escherichia coli, Staphylococcus aureus, Pseudomonas aeruginosa, Staphylococcus epidermidis and Klebsiella pneumoniae.

\section{EXPERIMENTAL}

\section{Microorganisms}

The clinically isolated microorganisms (Escherichia coli, Staphylococcus aureus, Pseudomonas aeruginosa, Staphylococcus epidermidis and Klebsiella pneumoniae) were obtained from Department of Biotechnology, Dr. N.G.P Arts and Sciences College, Coimbatore, Tamilnadu, India.

\section{Silver Nanoparticles and Chemicals}

The spherical in shape with an average size of 30-60 nm green synthesized AgNPs ${ }^{15}$ was a kind gift (Dr. Ranjithkumar R, Department Biotechnology, Dr. N.G.P. Arts and Science College, India). Also, Ranjithkumar et al (2013) reported that the green synthesized silver nanoparticles coated textile shows good antibacterial activity against human pathogens. ${ }^{8}$ Mueller-Hinton agar and other chemicals utilized were of analytical grade and were obtained from a local source.

\section{Preparation of AgNPs coated IVC (AgNPs-ICV)}

Silver nanoparticles releasing intravascular catheters were made using the slurry-dipping technique. The technique started with the preparation of stable slurry with $0.5 \mathrm{~g}$ of AgNPs in the molten polyethylene glycol (PEG). Appropriate slurry temperature $\left(37^{\circ} \mathrm{C}\right)$ was determined by an optimization process based on a trial-and-error approach to achieve optimum coating thickness, uniformity and stability of composite coating as well as adequate infiltration of AgNPs particles into coating structure. PEG (2g) with a predefined molecular weight was mixed with AgNPs $(0.5 \mathrm{~g})$ in a glass vial. The mixture was heated at the range of $60-70^{\circ} \mathrm{C}$ in a water bath to obtain a homogeneous slurry. The resulting slurry was homogenized in a magnetic stirrer for 5 to $10 \mathrm{~min}$. Each piece of the catheter (length $6 \mathrm{~mm}$ ) was dip-coated twice with intermittent drying (suspension coating method).

The dip-coating procedure was carried out in sterile glass beakers on a shaker $(120 \mathrm{rpm})$ for $30 \mathrm{~min}$, with a drying period of about $15 \mathrm{~min}$ between the two coating procedures, followed by drying at room temperature. All coating steps were carried out under strict aseptic conditions. All samples were coated by a thickness of about $3-10 \%$ of catheters outer diameters and the catheter samples were stored at $4^{\circ} \mathrm{C}$ for up to $15 \mathrm{~min}$. In order to increase AgNPs loading and prevent an excessive increase in catheter thickness, the coating process was repeated four times for each sample. Subsequently, in order to slow down the release rate of AgNPs from PEG coating and mitigate the friction effect between catheter surface and mucosa, the second coating layer was formed on the catheter surface.

PVA was dissolved in DMSO to acquire a $10 \mathrm{w} / \mathrm{w} \%$ solution. PEG-coated samples were submerged into PVA solution three times for $1 \mathrm{~min}$ each. Thereafter, these samples were stored at $0^{\circ} \mathrm{C}$ or in a deep freezer to implement one freeze-thaw cycle and physically crosslink the samples. The coated intravascular catheters were left to dry on a clean bench for one week at room temperature to remove residual DMSO.

\section{Antibacterial activity of AgNPs coated IVC}

The method was performed by analyzing the antibacterial activity of catheter materials after dip-coating with AgNPs. In this qualitative method the pre-measured size (length: 6mm) of all dip-coated catheter materials were tested, all coated materials were placed on the surface of Mueller-Hinton agar plate which had previously been seeded with an overnight broth culture of the test organisms. The plates were incubated at $37^{\circ} \mathrm{C}$ for 24 to $48 \mathrm{~h}$. The experiment was carried out in triplicate. Antibacterial activity was expressed as the diameter of the zone of inhibition.

\section{Persistence Test}

Serial Plate Transfer Test (SPTT) was performed to determine the persistence of AgNPs content in the biomaterial during the implantation period. The test was performed after the qualitative antibacterial activity. The SPTT was a test used to assess both the presence of antibacterial activity and its duration. 
It has also been used in the detection of resistance in adherent bacteria after prolonged exposure ${ }^{16}$. Briefly, using a sterile swab the overnight broth culture of the test organisms were swabbed on sterile Mueller-Hinton agar (MHA) plates. Each biomaterial coated with the AgNPs was placed on the seeded MHA plate and incubated at $37^{\circ} \mathrm{C}$ for $24 \mathrm{~h}$. The zone of inhibition was measured and the AgNPs coated biomaterial was immediately transferred to the next MHA plate seeded with similar test bacteria. It was ensured that the same material surface was in contact with the MHA surface. The process was continued until no more inhibitory zone was observed for the biomaterial.

\section{RESULTS AND DISCUSSION}

Antibacterial activity of after dip-coating with synthesis AgNPs catheter materials shows good antibacterial activity against test pathogen. In this present study, the antibacterial activity of IVC-AgNPs was evaluated by using standard Zone of Inhibition (ZOI) microbiology assay. Earlier some researcher indicates the organisms record frequently and isolated from catheter biofilms are $S$. epidermidis, $S$. aureus, $P$. aeruginosa, K. pneumoniae and E. faecalis. ${ }^{17}$ In this current experiment, plant assisted silver nanoparticles coated biomedical product exhibit signification antibacterial properties against biofilm producing pathogens and compare with the non-coated biomedical product, the diameter of inhibition zones increased for the test pathogens $S$. epidermidis and K. pneumoniae.

Antibacterial nanoparticles such as chitosan and nanoparticles coated chitosan exhibit significant antibacterial activity. ${ }^{18}$ The silver nanoparticles interact with multiple targets in the microbial cell, such as cell members, enzymes and plasmids, simultaneously providing the bacteria least capacity to gain resistance. ${ }^{4,8}$ In the present study, IVC-AgNPs biomaterial achieved maximum ZOI was found to be 42 $\mathrm{mm}$ and $36 \mathrm{~mm}$ for S. epidermidis and K. pneumoniae (Fig.-1).

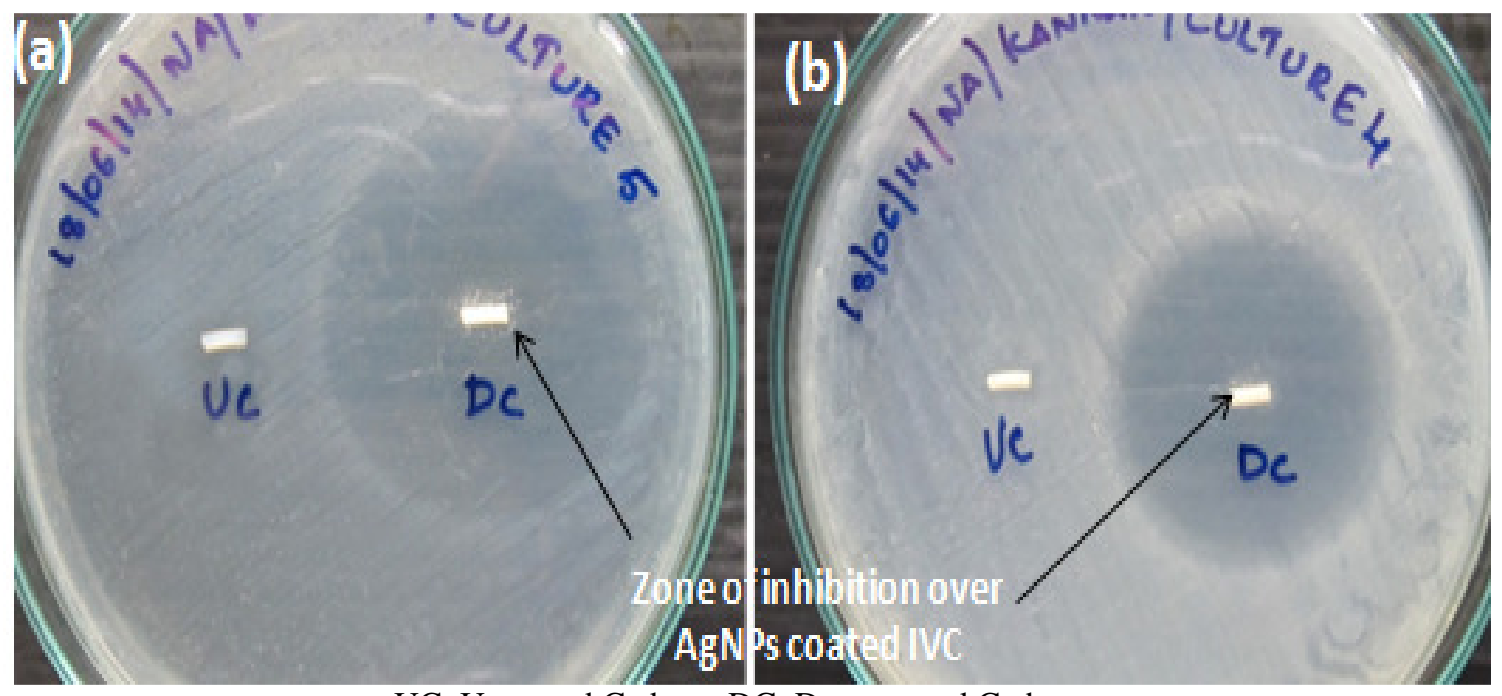

UC: Uncoated Catheter DC: Drug-coated Catheter

Fig.-1: AgNPs-IVC against biofilm producing organisms a) S. epidermidis and b) K. pneumoniae

Whereas, the other three bacteria strains of $S$. aureus, E. coli and $P$. aeruginosa showed a zone of inhibition of 31, 28 and $27 \mathrm{~mm}$ respectively, (Fig.-2). Conversely, no inhibition found in non-coated biomaterial. The AgNPs-IVC showed inhibition zone against all the studied bacteria and we found the AgNPs coated biomaterial has a superior antibacterial action against S. epidermidis and K. pneumoniae. In SPTT study, IVC-AgNPs shows the long duration of activities up to Day $8^{\text {th }}$ against $K$. pneumoniae and $S$. epidermidis. Whereas, AgNPs-IVC sample exhibit continued inhibition of all tested biofilm producing bacteria except $P$. aeruginosa and $S$. aureus. AgNPs impregnated IVC sample showed a zone of inhibition to Day $5^{\text {th }}$ against $S$. aureus (Fig.-3). 
RASĀYAN J. Chem.

Vol. 11 | No. 1 |63-68 | January - March | 2018
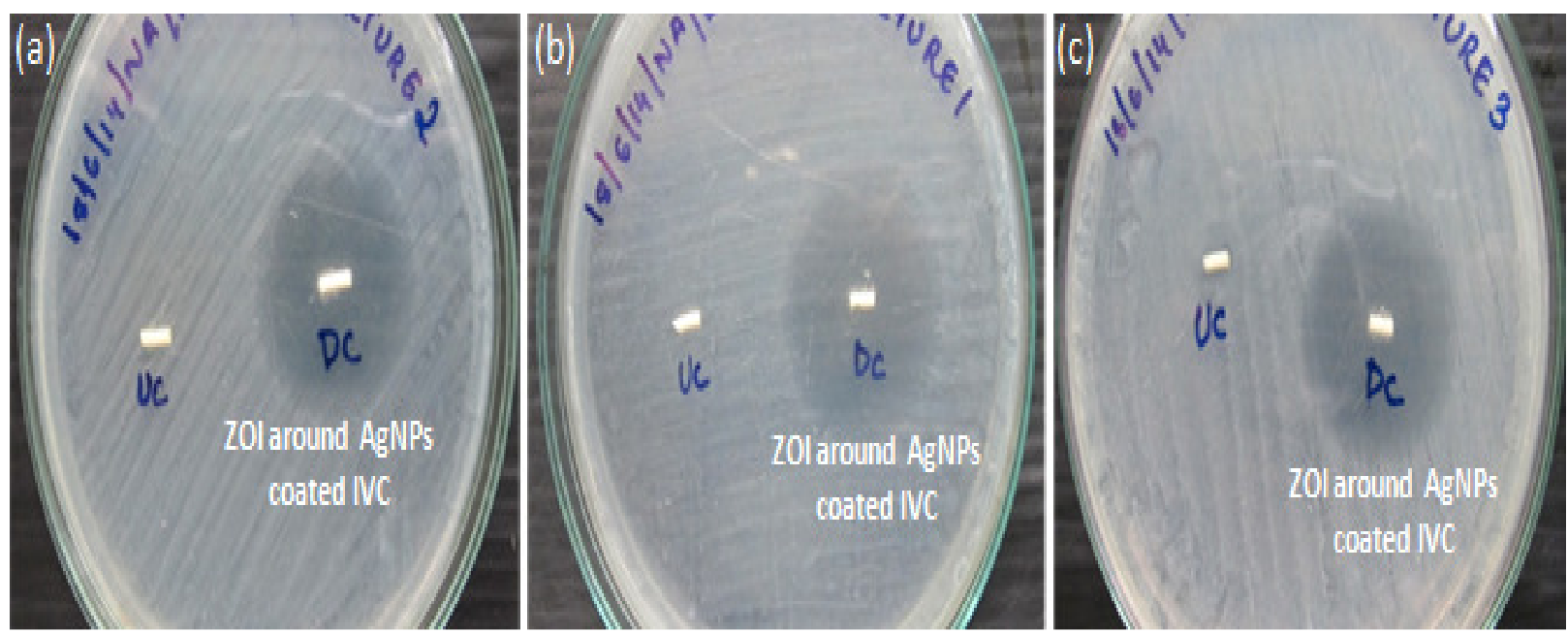

UC: Uncoated Catheter DC: Drug-coated Catheter

Fig.-2: AgNPs-IVC against biofilm producing organisms a) $S$. aureus b) E. coli and c) $P$. aeruginosa

However, in this present experiment achieved that the AgNPs coated biomaterial received continued zone of inhibition round $9 \mathrm{~mm}$ on Day $8^{\text {th }}$ against $S$. epidermidis (Fig.-4).

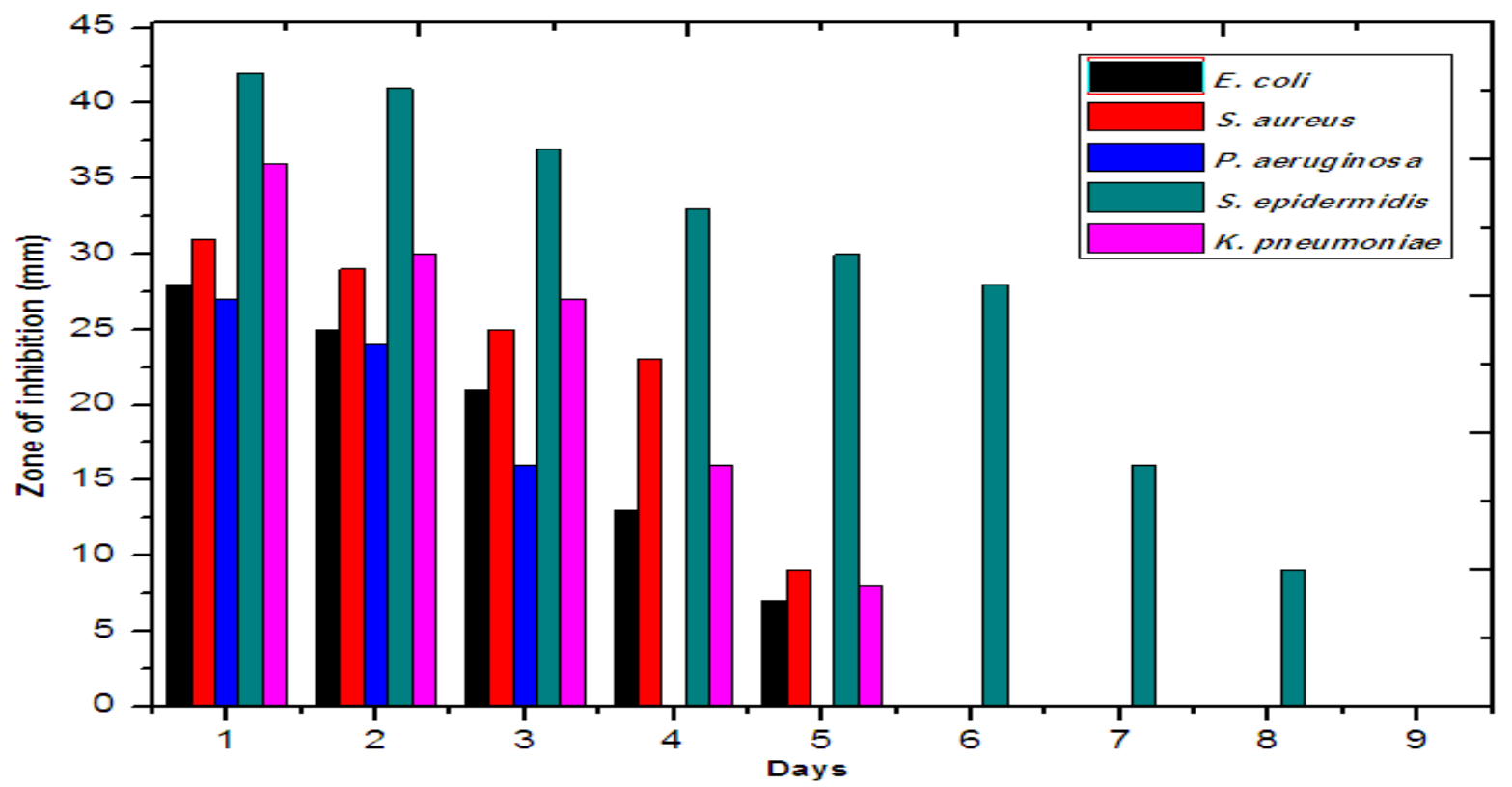

Fig.-3: SPTT on AgNPs coated IVC

\section{CONCLUSION}

Nanotechnology has emerged due to the integration of biotechnology with nanotechnology for developing biosynthetic and environmental-friendly technology for the biological application. In this present study, concentrate on the control of biofilm producing bacterial on the biomedical product using silver nanoparticles coated IVC (AgNPs-IVC). Results obtained from the present investigation reveals AgNPsIVC are potential antibacterial activity against tested pathogens particularly the diameter of inhibition zones increased for the test pathogens $S$. epidermidis and $K$. pneumoniae. The present study clearly explained biomedical product with a specific concentration of AgNPs showed a maximum activity against biofilm producing organisms. To utilize these potential bioinspired silver nanoparticles may assemble or coated on the biomedical product to prevent biofilm formation (Schematic-I). 


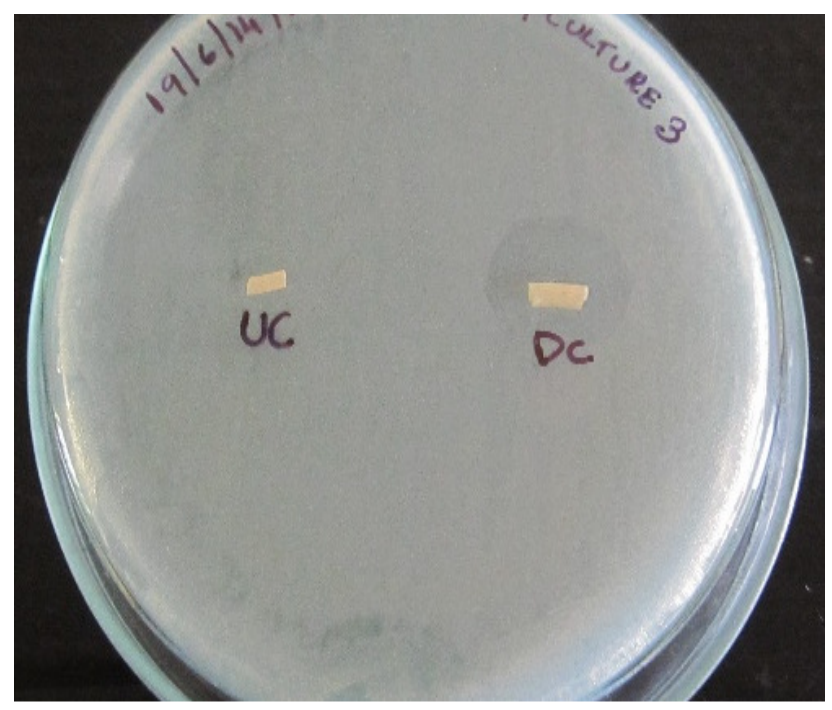

Fig.-4: AgNPs impregnated IVC on $8^{\text {th }}$ Day against S. epidermidis

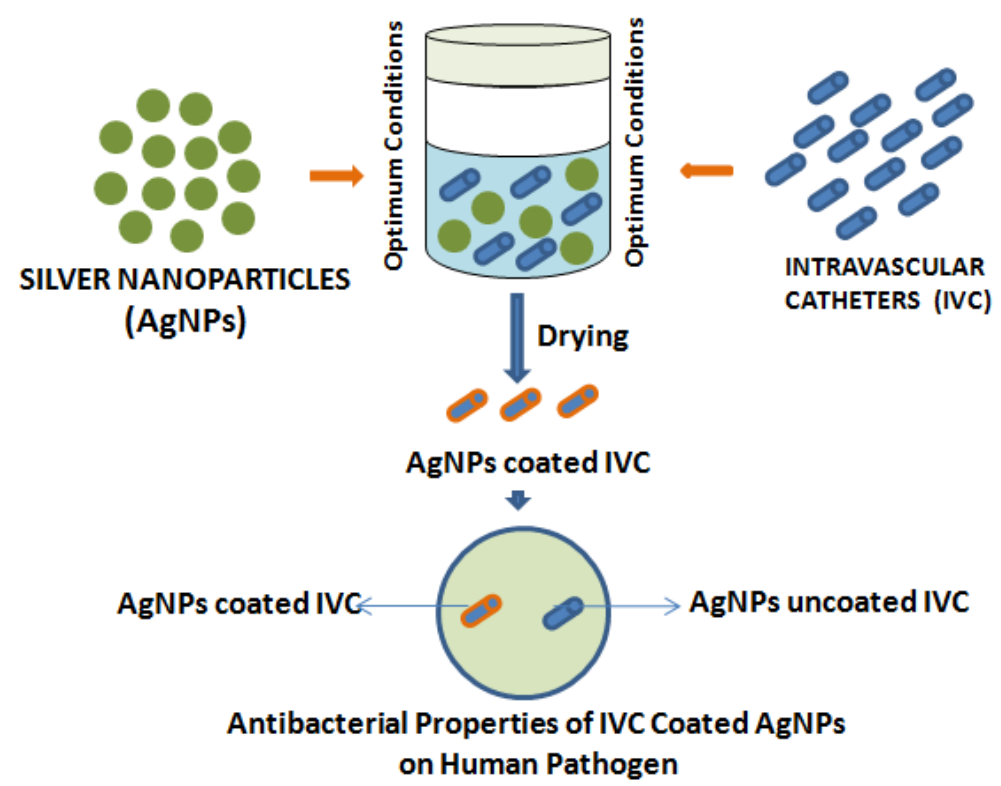

Scheme-1: Diagrammatic presentation of IVC coated AgNPs against biofilm producing human pathogen by dip coating method

\section{REFERENCES}

1. A. Sousa, I. Machado, and M. O. Pereira, Communicating Curr. Res. and Technological Adv., 1, 878 (2011).

2. J. Theron, J. A. Walker, and T. E. Cloete, Critical Rev. in Microbiol., 34(1),43 (2008).

3. Q. Li, S. Mahendra, D. Y. Lyon, L. Brunet, M. V. Liga, D. Li, and P. J. J. Alvarez. Water Research 42(18), 4591 (2008).

4. R. Ranjithkumar, K. Selvam, P. Sagadevan, and B. Chandar Shekar, Int. J. Biosci. Nanosci. 2(8), 185 (2015).

5. R. Ranjithkumar, B. Chandar Shekar, C.K. Senthil Kumaran, C. Sharman, and V. Simi. Kong. Res. J. 2(2), 6 (2015).

6. A. Jesline, P. J. Neetu, and P.M. Narayanan, Appli. Nanosci., 5,157 (2015) 


\section{RASĀYAN J. Chem.}

Vol. 11 | No. 1 |63-68 | January - March | 2018

7. P. Julia, Y. Chevalier, J. Pelletier, E. Couval, D. Bouvier, and M. A. Bolzinger, Collids and Surface A, 457, 263 (2014).

8. R. Ranjithkumar, K. Selvam, and M. Shanmugavadivu. J. Green Sci. Technol. 1(2), 111 (2013).

9. M. R. Bindhu, and M. Umadevi, Mat. Lett, 120,122 (2014).

10. J. P. Guggenbichler, M. Boswald, S. Lugauer, and T. Krall. Infection, 27, S16 (1999).

11. Haytham M.M. Ibrahim, J. Radiation Res. Appl. Sci. 8(3), 265 (2015).

12. B. S. Hungund, G. R. Dhulappanavar, and N. H. Ayachit, J. Nanomed. Nanotechnol. 6(271), 1 (2015)

13. R.O Darouiche, I.I. Raad, S. O. Heard, J. I. Thornby, O. C. Wenker, A. Gabrielli, J. Berg, N. Khardori, H. Hanna, R. Hachem, R. L. Harris, and G. A. Mayhall,. N Engl J Med. 340, 1 (1999).

14. M. Wilcox, P. Kite, and B. Dobbins, J. Hosp. Infect. 38,322 (1998).

15. R. Ranjithkumar, K. Selvam, and M. Shanmugavadivu, J. Green Sci. Technol., 1(2), 102 (2013).

16. R. Bayston, L.E. Fisher, and K. Weber. Biomaterials, 30(18), 3167 (2009).

17. H. Rohde, S. Frankenberger, U. Zahringer, and D. Mack,. Eur. J. Cell Biol., 89,103 (2010).

18. R.P. Senthil Kumar, V. Bhuvaneshwari, R. Ranjithkumar, V. Malayaman, S. Sathiyavimal, and B. Chandar Shekar, Int. J. Biological Macromolecules, 104, 1746 (2017).

[RJC-1934/2017] 